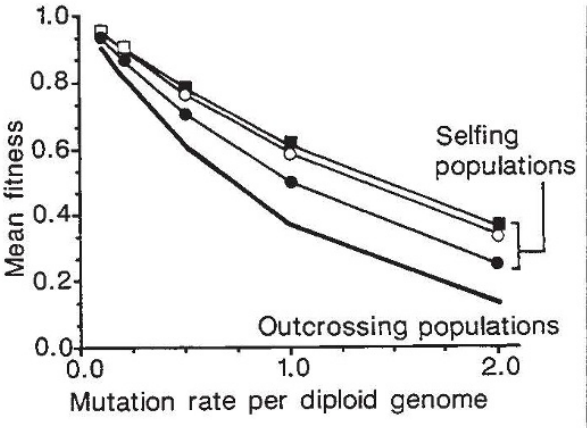

Mean fitness of a completely outcrossing population at its equilibrium under mutation to deleterious partially recessive alleles at many loci, compared with the corresponding mean fitness of populations reproducing only by self-fertilization, with different mutation rates per diploid genome. The outcrossing mean fitness does not depend on the type of selection or the values of the selection parameters, so only a single line is shown. For the selfing cases, results for various values of the selection coefficient of a mutant allele (s), and the dominance coefficient $(h)$ are: black circles, $s=0.5, h=0.5$; open circles, $s=0.2$, $h=0.2$; squares, $s=0.01, h=0.2$.

for growth and survival to the next season; they are therefore expected to have a low rate of reproduction and thus produce few seeds per unit mass of plant in any one season ${ }^{16}$. Why then do they have many flowers and ovules? This can be accounted for in terms of the male fertility component of fitness through pollinator attraction $^{17,18}$. It is then surprising that plants do not frequently produce some flowers with purely male function and become andromonoecious. Total loss of female function of flowers may be disadvantageous because of uncertainty of the pollination process; unless each flower has a high chance of getting fertilized, or unless fruits are very costly of resources (for example very big), maximum-realized fertility cannot be achieved from a few flowers ${ }^{19.21}$.

Another interpretation is that outcrossers suffer high genetic loads, causing many fertilization products to abort early in development ${ }^{2 \mathrm{t}}$. (Genetic load is the relative lowering of the mean fitness of a population compared with the fitness of the best possible genotype.) Genetic loads are thought to result mainly from mutation to harmful partially or fully recessive alleles such as recessive lethals, and possibly also to alleles maintained by heterozygote advantage ${ }^{22}$. The second type of genetic load is least with outcrossing and increases somewhat with self fertilization (selfing), presumably because heterozygote advantage helps maintain variation in populations even though homozygotes produced by selfing are at a disadvantage. This type of gene action cannot therefore explain the low fecundity of outcrossing species.

With genetic load resulting from mutation, mean fitness increases as selfing increases because the equilibrium fre- quences of deleterious alleles are reduced. The total genetic load in a wholly selfing population can be much lower than in a completely outcrossing population when the mutation rate is high, so that individuals in the outcrossing population are heterozygous for many mutant alleles depressing fitness (see figure). It seems unlikely that all this load will be expressed in the earliest stages of development so as to be detectable as reduced seed maturation, but this view might be wrong, as this is an important developmental stage. It is not known what proportion of plant genomes are expressed in the seed stage; certainly many mutations are known that affect seed (embryo and endosperm) characters ${ }^{23.24}$.

If mutational load contributes to the loss of fertilization products in outcrossing plants, the abortion of individual seeds will be determined by the zygote genotypes; it should be random within fruits, and its frequency should be affected by the maternal and paternal parents, and by interaction between them ${ }^{25}$. Furthermore, in outcrossing populations with mutational load including partially or fully recessive alleles, strong inbreeding depression would be expected; in $D$. eurekensis Wiens et al. find that outcrossed flowers produce more mature seeds than selfed ones, but the difference is not statistically significant. This hypothesis could also account for the correlation between longevity and low female fecundity if longlived species have higher mutation rates, as has recently been argued ${ }^{26}$.

Deborah Charlesworth is in the Department of Ecology and Evolution, University of Chicago, Chicago, Illinois 60637, USA.

1. Wiens, D.C., Nickrent, D.L., Davern, C.I., Calvin, C.L. \& Vivrette, N.J. Nature 338, 65-67 (1989)

2. Bierzychudek, P. Am. Nat. 117, 838-840 (1981).

3. Bertin, R.I. Am. J. Bot. 69, 124-134 (1982).

4. Bertin, R.I. Am. J. Bot. 75, 1140-1147 (1988)

5. Shore, J.S. \& Barrett, S.C.H. Can. J. Bot. 62, 1298-1303 (1984).

6. Snow, A.A. Oecologia (Berlin) 55, 231-237 (1982)

7. McDade, L.A. \& Davidar, P. Oecologia (Berlin) 64, 61-67 (1984)

8. Stephenson, A.G. A. Rev. Ecol. Syst. 12, 253 (1981).

9. Sutherland. S. \& Delph, L.F. Ecology 65, 1093 (1984)

10. Mazer, S.J. Evolution 41. 355-371 (1987).

11. Stanton, M.L., Bereczky, J.K. \& Hasbrouck, H.D. Oecologia (Berlin) 74, 68-76 (1987)

12. Wiens, D. Oecologia (Berfin) $64,47-53$ (1984).

13. Sutherland, S. Evolution 40, 117-128 (1986).

14. Ridley, M. The Explanation of Organic Diversity: the Comparative Method and Adaptations for Mating (Oxford University Press, 1983)

15. Felsenstein, J. Am. Nat. 125, 1-15 (1985).

16. Primack, R.B. Am. Nat. 114, 51-62 (1979)

17. Queller, D.C. Nature 305, 706-707 (1983)

17. Queller, D.C. Nature 305, 706-707 (1983).

19. Bertin, R.K. Evol. Theor. 6, 25-32 (1982).

20. Whalen, M.D. \& Costich, D.E. in Solanaceae: Biology and Systematics (ed. D'Arcy, W.G.) 284-305 (Columbia University Press, New York, 1986)

21. Wiens, D. et al. Oecologia (Berlin) 71, 501-509 (1987).

22. Charlesworth, D. \& Charlesworth, B. (A. Rev, Ecol. Syst. 18, 237-268 (1987).

23. Mendel, G. Verh. des Naturforsch. Ver. Brünn 4, 3-47 (1865)

24. Meinke, D. et al. in Plant Genetics (ed. Freeling. M.) 129-146 (Liss, New York, 1985).

25. Mazer, S.J., Snow, A.A. \& Stanton, M.L. Am. J. Bot. 73 500-511 (1986).

26. Klekowski, E.J. Mutation, Developmental Selection, and Plant Evolution (Columbia University Press, New York. 1988).

\section{Surprising damp}

Daedalus once devised an anti-condensation paint for kitchens and bathrooms. It was based on the 'hydrogel' polymers used for soft contact lenses; these readily absorb water, swelling somewhat as they do so. A hydrogel paint can thus absorb sudden peaks of condensation, and slowly breathe it out again as vapour in periods of low humidity. With the walls and ceiling of the whole room as an absorption surface, many litres of condensation can be taken up.

The problems began when Daedalus tried to colour his new product for the domestic market, by mixing it with a rather hastily formulated emulsion paint. In a cold, damp room the new mixed paint certainly took up water vapour very efficiently. But when the room was warmed up to reduce its relative humidity, condensation actually oozed from the painted surface and ran depressingly down the walls. It turned out that the liquid emulsion droplets dispersed in the paint had solidified in the cold test room. On warming up, they melted again, expanding strongly as melting vegetable oils do. The water-swollen hydrogel was thus suddenly and forcefully pressurized from within, and its loading of liquid water was squeezed out of it by reverse osmosis. Daedalus had invented a condensation generator.

DREADCO's marketing department soon rose to the challenge of this new product. Wet Paint ${ }^{\circledR}$ is being aimed at the car and vehicle market. The weekly wash and polish beloved by devout car-owners is mainly symbolic: corrosion starts at internal seams and surfaces no owner can reach. But a Wet-Painted car will never need to be cleaned at all. Every night, as the temperature falls and humidity rises, its surface will absorb water vapour; every day, as the temperature rises, it will weep the water out again as a liquid. Coming out of the paint surface itself, the exuded water will clean far more efficiently than any external spray. Dirt and road salt will simply be dislodged from beneath and floated away. Applied to trains, houses, bridges, and many other external structures, Wet Paint will keep grime, mould and graffiti at bay. The whole urban environment will be wonderfully smartened up.

Some technical problems remain to be solved, of course. During its pressureexudation phase, Wet Paint tends to weep not only at its outer surface, but also at its inner one, thus pumping itself forcefully off the wall. Reliable bonding to substrate or undercoat is needed. On the other hand, DREADCO's cosmeticists hope to apply this principle in a new and powerful moisturizing cream. Unique among such preparations, it will take up moisture from the air and force it into the wearer's skin under many atmospheres of hydraulic pressure.

David Jones 